\title{
THE ESTABLISHMENT OF A PROGNOSIS FOR GENITO-SEXUAL FUNCTION IN THE PARAPLEGIC AND TETRAPLEGIC MALE
}

\author{
By J. B. PIERA \\ Neurological Re-education Department, Professor A. Grossiord, Raymond \\ Poincare Hospital, Garches 92, France
}

IT is now possible to assess genital and sexual potential in the paraplegic and tetraplegic male, provided the neurological picture, and to be more exact, the state of the lumbo-sacral spinal cord from Tro to $S_{4}$, is taken into account. The pivotal role of the latter is corroborated by what is known about genito-sexual physiology, which in outline is as follows:

(I) Erection. Erection is an active vasodilative phenomenon which seems to depend on the spinal parasympathetic system $\left(\mathrm{S}_{2}, \mathrm{~S}_{3}, \mathrm{~S}_{4}\right)$ and is mediated by the erector nerves of Eckardt.

(2) Ejaculation. Expulsion of sperm from the urogenital tract is a complex phenomenon which may be artificially divided into two phases.

(a) Accumulation of Spermatozoa in the Posterior Urethra. This cumulative process seems to depend on the lumbar orthosympathetic system (the first three myelinated communicating branches and the lumbar sympathetic ganglia) through the pelvic splanchnic nerves and the hypogastric plexi.

(b) Spasmodic Erection of Spermatozoa. Ejaculation depends on the genital nerves, which arise in the $\mathrm{S}_{2}, \mathrm{~S}_{3}$, and $\mathrm{S}_{4}$ myelomeres. Intravesicular retrograde ejaculation is prevented by closure of the neck of the bladder.

The two phases must be coordinated and therefore require the existence of a perfect functional bridge between the lumbar and sacral spinal cord.

The existence of sensitive pathways which permit reflex function complicates this outline (fig. I).

With respect to spermatogenesis, it should not be forgotten that the pituitary hormones in the blood are not in themselves sufficient to ensure good trophic function in the seminal tubes. Many other factors play a part in this, such as: (a) the integrity of the testicular sympathetic system; (b) vascularisation and (c) mechanical factors.

It is evident that a paraplegic may be sterile for reasons not related to his neurological impairment (varicocele, Klinefelter's syndrome, and so on).

Establishment of a Prognosis. Data obtained through questioning during personal interviews aids in establishing a prognosis. But evaluation of the outlook is based, above all, on the findings of the neurological examination together with exploration of the real potential of the patient. In the latter, the intrathecal prostigimine test, advocated and carefully researched by Guttman and Walsh (I97I) is an indispensable part of the genito-sexual evaluation; the author has invariably included it. 


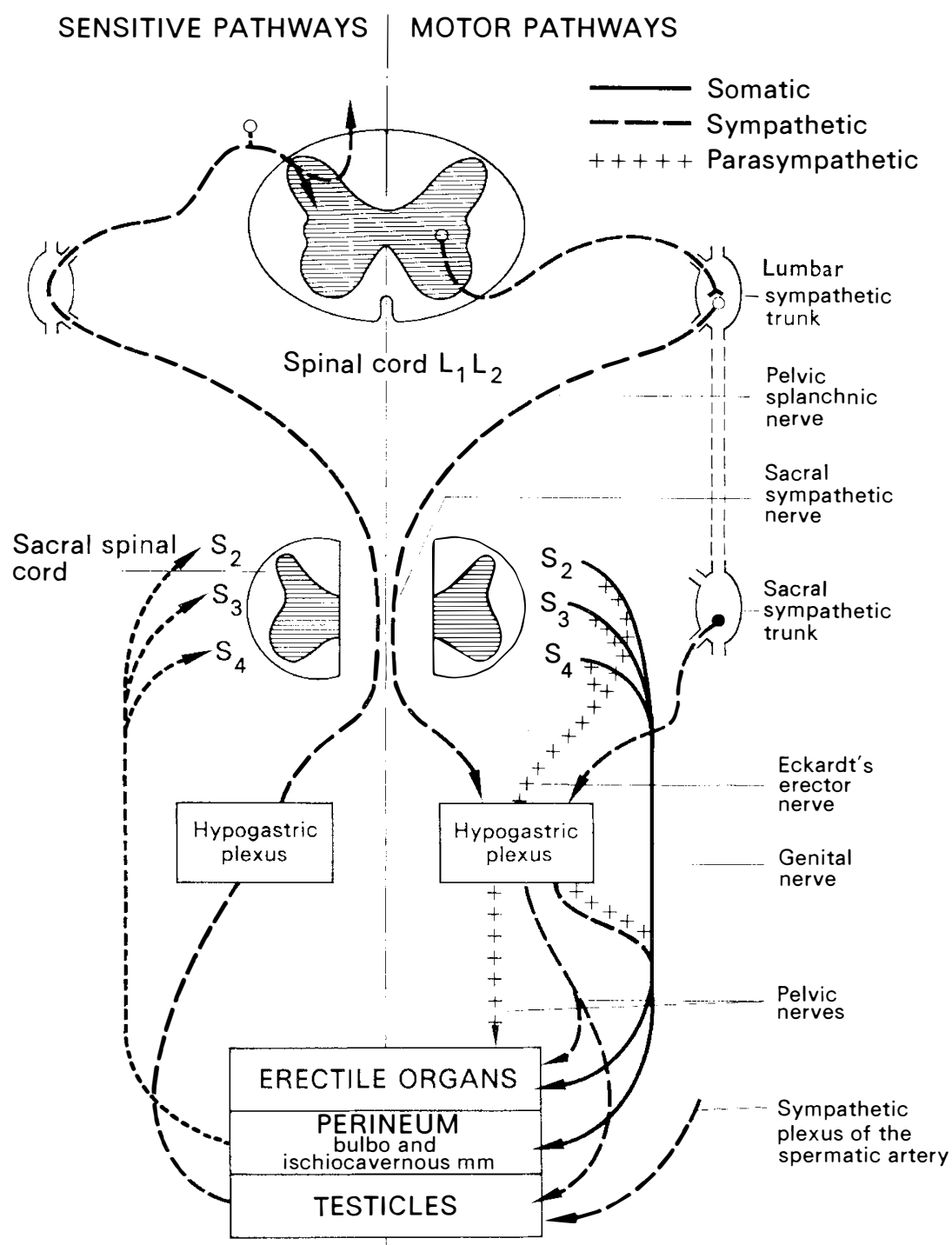

FIG. I

It is the author's opinion that a specialised consultation to establish the prognosis should not take place too soon. It is essential to wait for: (a) neurological stabilisation of the spinal lesion; (b) a satisfactory trophic state and (c) complete retraining of the bladder. The most favourable period lies just before discharge from the retraining centre. The patient should be seen by the physician at regular intervals until he has resumed an as near normal family life as possible. 
Questioning.

Information learned from personal interviews with the patient is of fundamental importance. It is the author's practice to begin these interviews with questions about urinary and rectal functions, as he finds these easier to broach directly. The following are covered:

vesical, urethral and anal sensitivity, modality of voiding and defecation (reflex or voluntary),

medical history, especially,

infections, which might affect the production or progression of spermatozoa (orchiepididymitis, urethrocoele, etc.).

therapeutic measures such as intranervous alcohol injections or resection of the genital or sacral nerves.

\section{Then Sexual Function is Explored}

Reason for the consultation; paraplegics tend to be more concerned by sexual problems than by their reproductive capacity.

Sexual desire (libido), which is generally unchanged.

Erections. The way in which they are elicited, the patient's self-perceptions, the quality (whether they enable sexual contacts or not) should be described.

Ejaculations. How they are elicited and whether or not orgasm is experienced should be established.

The points cited above represent only the main features of the questioning which requires considerable skill and care if valid data is to be obtained. There must also be:

Trust. The patient must trust the examiner if he is to give accurate answers to questions which are often very intimate.

Patience. The examiner must be patient. This is necessary if only for semantic reasons; the patient is often unfamiliar with technical terms or mistaken in his usage.

Accuracy. The description of the phenomena reported must be accurate. Patients may believe that emission of a few drops of clear or purulent liquid constitutes an ejaculation.

Psychological factors must also be considered, such as

Timidity: inhibitions,

Anxiety: shame about all aspects of his sex life as the result often unjustified feelings of incapacity.

\section{Physical Examination of the Patient.}

The information from the interview, which is always less reliable, should be compared with the data obtained from physical examination of the patient. The examination should cover:

(I) The Characterisitics of the Paraplegia. Upper limits of the spinal cord lesion to motor and sensitive functions.

Possible spasticity and especially, the upper limits of the spasticity as determined by observation of reflexes and the extent of rigidity.

(2) The Functional State of the Upper Lumbar and Sacral Spinal Cord. The genito-sexual prognosis will depend on this aspect. 
(a) A conclusion of complete section requires that in so far as the sacral portion of the spinal cord is concerned,

there may be a total absence of all peripheral sensitivity, including proprioception, which should be examined at the ischia and the coccyx, the absence of all specific sensitivity in the bladder, urethra and rectum, lack of voluntary control of the pelvic muscles, incontinence, inability to interrupt a stream of urine or to close on the finger introduced into the anal canal during rectal palpation.

(b) A peripheral lesion should be diagnosed when the following is seen, in addition to the lack of all reflex action,

for the upper lumbar spinal cord, lack of the cremasteric reflex,

for the sacral spinal cord, the absence of perineal reflexes: the bulbocavernous reflex $\left(S_{3}\right)$ and the anal reflex $\left(S_{4}\right)$; a gaping unwrinkled anus, which does not contract on coughing; a 'flat' cyctometrogram; a negative ice-water test and in case of doubt, electrical stimulation and electromyography of the anal sphincter complete the exploration.

After having drawn the most accurate conclusions possible from this neurological evaluation, the actual capacity of the patient in the sexual and genital areas must be determined.

(I) Reflex erections will often be seen during examination of the genitals. The patient generally can provoke them easily through masturbation or other stimulation.

(2) Ejaculations. The patient is asked to elicit an ejaculation while alone. There are two possible results:

(a) ejaculation takes place after stimulation which may be more or less protracted. The ejaculate is then examined immediately.

(b) ejaculation does not take place despite repeated attempts. In this case, it is suggested to the patient that an intraspinal injection of prostigmine (neostigmine) be administered during a 24 or 48 -hour hospitalisation. Injection of a small dose, intradurally, of $0.3 \mathrm{mg}$. to $0.5 \mathrm{mg}$, elicits erection and ejaculation which are often repeated. In certain cases with strong spasticity, vomiting (the subject should refrain from food before the test), transitory retention of urine and autonomic hyperreflexia may occurr.

If no ejaculation is elicited, prostate massage will often yield a few drops of prostatic fluid which is more or less rich in spermatozoa. In case of failure, the possibility of retrograde ejaculation into the bladder would be eliminated by examining the first urine voided or by irrigation of the bladder. The author has rarely encountered this.

\section{RESULTS}

A group of 100 paraplegic and tetraplegic patients was studied. A complete evaluation was made for each, including an intrathecal prostigimine test if ejaculation could not be elicited by simple stimulation.

Generally, erections were more frequent than ejaculations. However, the findings do not take on their full significance unless broken down according to the type of lesion in the lumbo-sacral spinal cord: complete or incomplete, spastic or flaccid (Table I). 
TABLE I

Genito-sexual functions in roo paraplegics and tetraplegics

\begin{tabular}{|c|c|c|c|c|c|}
\hline Lesion & No. & Erections & Ejaculations & Coitus & Children \\
\hline Complete spastic & 52 & 49 & 22 & 2 I & 0 \\
\hline Complete flaccid & I5 & 0 & 0 & 0 & 0 \\
\hline Incomplete spastic & 20 & I9 & I3 & I2 & 0 \\
\hline Incomplete flaccid & I3 & II & 9 & 6 & 2 \\
\hline Totals & I00 & 79 & 47 & 39 & 2 \\
\hline
\end{tabular}

\section{Complete Spastic Lesions}

Reflex erections are the rule, elicited by the slightest stimulation. Ejaculations are far more infrequent, being found in little more than a third of the cases, if those elicited by intrathecal prostigmine are included. Coitus is possible provided the problems inherent in the patient's motor handicaps are resolved and that the erection is sustained. Erection and ejaculation are not perceived by the patient. The latter may precipitate abrupt sedation of the rigidity and manifestations of autonomic hyperreflexia.

Giving special attention to the possibilities of reflex ejaculation obtained by (I) masturbation or vibro-massage or (2) intrathecal prostigmine; it appears that results vary with the neurological level of the lesion, and more precisely, with the upper limit of the spastic phenomena (the upper limit of the sub-lesional syndrome and the manifestations of reflex depending on spinal mechanisms).

(a) Manifestations of spinal cord mechanisms going up to Tro (i.e., above the genito-sexual centres).

Ejaculation is possible. In certain cases, it may be obtained by simple stimulation during erection; in others, intrathecal prostigimine is required. The prostigmine in fact only unmasks reflex function of the ejaculatory centres. The quality of the spermatozoa is generally mediocre, if not in number, at least in their mobility which is almost always greatly reduced.

(b) Manifestations of spinal cord mechanisms remaining below Tro.

Ejaculation is not elicited either by masturbation or vibromassage, or by intrathecal injection of prostigmine. (When an ejaculation is elicited, the spinal cord lesion is often shown to be incomplete on further careful neurological examination.) (Table IIA).

The Tro boundary is not absolute, because the upper limit of spasticity is not always easy to determine. A good prognosis is indicated for ejaculation if $(a)$ cremasteric reflexes are demonstrated $\left(\mathrm{T} \mathrm{I}_{2}, \mathrm{LI}\right)$ and $(b)$ the existence of rigidity in the lower abdominals is seen (Tio, Ti2). 


\section{Complete Flaccid Lesions.}

If the lesion is complete at the level of the lumbo-sacral spinal cord, the prognosis is very poor. There is no possibility of erection or ejaculation, as seen in Table II (B). However, if the lesion is complete but below $\mathrm{S}_{3}$ erection and ejaculation will be possible.

\section{Incomplete Spastic Lesions.}

The findings for these patients are given in Table II (C).

Though more mechanical than psychogenic, erections are the rule and are often accompanied by an ejaculation. The latter may not occur under the effects

\section{TABLE II}

Results of examinations

\begin{tabular}{|c|c|c|c|c|}
\hline Type of lesion & $\begin{array}{l}\text { No. } \\
\text { cases }\end{array}$ & $\begin{array}{l}\text { Ejaculation with } \\
\text { masturbation or } \\
\text { vibromassage }\end{array}$ & $\begin{array}{c}\text { Ejaculation } \\
\text { with intrathecal } \\
\text { prostigmine }\end{array}$ & $\begin{array}{l}\text { Failure with } \\
\text { intrathecal } \\
\text { prostigmine }\end{array}$ \\
\hline $\begin{array}{l}\text { (A) } \\
\text { Complete spastic. } \mathrm{N}=52 \\
\text { Spasticity up to } \mathrm{T} \text { Io }\end{array}$ & 23 & 12 & 9 & 2 \\
\hline $\begin{array}{l}\text { Spasticity not } \\
\text { reaching TIO }\end{array}$ & 29 & 0 & I & 28 \\
\hline $\begin{array}{l}\text { Complete flaccid } \\
\text { Co }\end{array}$ & I6 & o & o & 16 \\
\hline $\begin{array}{l}\text { (C) } \\
\text { Incomplete spastic }\end{array}$ & 20 & IO & 6 & 4 \\
\hline $\begin{array}{l}\text { (D) } \\
\text { Incomplete flaccid }\end{array}$ & I3 & 5 & 4 & 4 \\
\hline
\end{tabular}

of masturbation or vibromassage, then intrathecal prostigmine is often very effective, depending on the extent of the motor lesion. In many cases, the prostigmine has a lasting effect on the attainment of ejaculations, as if it removed an inhibition. The sperm obtained is generally of good quality, which is better when the lesion is lower.

\section{Incomplete Flaccid Lesions.}

As may be seen in part D of Table II, and as in all incomplete lesions of the motor and sensitive fibres of the spinal nerves, the prognosis is better. Ejaculation is often possible, elicited by prostigmine if required. Two incomplete paraplegics at the Li level were able to have children. 


\section{CONCLUSIONS}

The prognosis for genital and sexual function in the paraplegic is closely tied to the neurological characteristics of the lesion in the lumbo-sacral spinal cord. Generally speaking, the prognosis is not as good for complete lesions, especially flaccid as it is for incomplete lesions.

It is very important to obtain a sperm sample from the patient, either by less drastic measures such as masturbation, vibromassage, prostate massage, administration of parasympathomimetics, or by more extreme measures such as intrathecal injection of prostigmine. The effects of the prostigmine are predictable: it will only elicit ejaculations in incomplete lesions (especially if section of the motor bundles is not complete), and in complete lesions, it elicits them only when spastic and the spinal mechanisms travel upward to about Tro. Certain patients

TABLE III

The results of intrathecal prostigmine injections in 74 patients

\begin{tabular}{|l|c|c|c|}
\hline & $\begin{array}{c}\text { Number } \\
\text { of cases }\end{array}$ & $\begin{array}{c}\text { Ejaculation with } \\
\text { intrathecal } \\
\text { prostigmine }\end{array}$ & $\begin{array}{c}\text { Failure with } \\
\text { intrathecal } \\
\text { prostigmine }\end{array}$ \\
\hline $\begin{array}{c}\text { Complete spastic lesions with } \\
\text { spasticity up to TIO } \\
\text { spasticity below TIO }\end{array}$ & I I & 9 & 2 \\
\hline Complete flaccid lesions & I6 & I & 28 \\
\hline Incomplete spastic lesions & IO & 6 & 46 \\
\hline Incomplete flaccid lesions & 8 & 4 & 4 \\
\hline
\end{tabular}

received up to three injections of prostigmine (Table III). Bearing this fact in mind, it is the author's opinion that it is useless to attempt an intrathecal injection of prostigmine when the lesion is complete and flaccid; or when the lesion is complete and spastic, but the manifestations of reflex spinal cord activity do not reach at least the Li level.

The quality of the spermatozoa is often mediocre, infertile and variable in the sense that it progressively becomes impoverished in quality as time passes. However, the quality does improve appreciably with repeated ejaculations, elicited by prostigmine if necessary.

If coitus is impossible and children are truly wanted, assisted insemination may be employed. In fact, if there is no ejaculation, the creation of a spermatocoele by surgery may be suggested (Schoysmann), provided the results of testicular biopsy are favourable. The author has had no experience with this procedure.

\section{SUMMARY}

The prognosis for genito-sexual functions in the paraplegic and tetraplegic male is closely linked to the neurological characteristics of the lesion in the lumbo- 
sacral spinal cord containing the ejaculation and erection centres. In complete spastic lesions, erection is possible but only as a mechanical reflex. Ejaculation, elicited if need be by intrathecal prostigmine, is possible if the manifestations of spinal mechanisms are seen up to Tro.

The quality of the spermatozoa is variable, but generally, mediocre. In complete flaccid lesions, neither erection not ejaculation is possible. In incomplete lesions, erection and ejaculation are often possible, elicited by prostigmine if required. The quality of the sperm is generally good and is found to be better when the lesion is lower.

\section{RÉSUMÉ}

Le pronostic des fonctions génito-sexuelles de l'homme para ou tétraplégique dépend étroitement des caractéristiques neurologiques de la lésion au niveau de la moelle lombosacrée qui abrite les centres médullaires de l'éjaculation et de l'érection.

Dans les lésions complètes spastiques l'érection est possible, uniquement reflexe. L'éjaculation, au besoin déclenchée par prostigmine intra-thécale est possible si les phénomènes d'automatismes medullaires remontent jusqu'au DIO environ.

La qualité du sperme est variable, généralement médiocre.

Dans les lésions complètes flasques: pas de possibilité d'érection ni d'éjaculation.

Dans les lésions incomplètes, érection et éjaculation sont souvent possibles, au besoin déclenchées par prostigmine intra-rachidienne; la qualité du sperme est en général bonne, d'autant meilleure que la lésion est plus basse.

\section{REFERENCES}

Bors, E. (I963). Sexual functions in patients with spinal cord injury in spinal injuries. Symposium in the Royal College of Surgeons of Edinburgh, 70.

Chapelle, P. A., Piera, J. B., Pannier, S., Lacert, P. \& Grossiord, A. (I97I). Fonctions génitales et sexuelles chez les paraplégiques. Revue du praticien, 21, 25, 3785-3794.

ComarR, A. E. (1970). Les fonctions sexuelles chez les paraplégiques. Urologia internat. 25, I34-I68.

Goldstein, M. (1966). L'impuissance sexuelle post-sympathectomie. Acta chirurg. 65, No. $7,800-803$.

Guttmann, L. (I953). Monograph in Vol. Surgery, Med. History of World War II. London: H.M. Stationary Office.

Guttmann, L. (196I). The sexual problem in spinal paraplegia. Proc. Scientific Meeting, intern. Stoke Mandeville Games, Rome, 63-69.

Guttmann, L. \& Walsh, J. J. (I97I). Prostigmin assessment test of fertility in spinal man. F. paraplegia, 9, I, 39-5I.

MAury, M. \& LACERT, Ph. (I97I). Traumatismes de la moelle épinière. Encyclopédié Méd. chir. Paris I 7685 AIO I.

Talbot, H. S. (1955). La fonction sexuelle dans la paraplégie. F. of Urol., 73, No. I, 9I-IOO. 